\title{
Morfologia e anatomia da flor de Pilocarpus pennatifolius Lem. (Rutaceae)
}

\author{
LUIZ A. SOUZA ${ }^{1,2}$, KÁTHIA S.M. MOURÃO ${ }^{1}$, ISMAR S. MOSCHETA ${ }^{1}$ e SÔNIA M. ROSA ${ }^{1}$
}

(recebido: 21 de março de 2001; aceito: 5 de fevereiro de 2003)

\begin{abstract}
Floral morphology and anatomy of Pilocarpus pennatifolius Lem. (Rutaceae)). Pilocarpus pennatifolius Lem. (Rutaceae) presents actinomorphics, dichlamydeous, nectariferous and monoclinous flowers, disposed in pendulous racemes. The anthesis is basipetal in the inflorescence and it is preferentially nocturne. The flower presents five stamens with tetrasporangiate anthers. The anther wall presents epidermis, endothecium, two middle layers and binucleate tapetum; the connective shows epidermis with stomata. The unipistilate gynoecium and compound by five carpels, which are joined at the base of the ovary and at the style and stigma. The style is short and solid and the stigma presents a papilose epidermis. The hemitropous, bitegmic and crassinucelate ovule presents a hypostasis and an obturator, which arises from funicle. The nectary surrounds completely the ovary base. Each sepal receives three vascular traces and the petals and stamens one trace. Each carpel receives a dorsal vascular bundle and two vascular ventral bundles that maintain their individuality throughout their course.
\end{abstract}

Key words - anatomy, anthesis, flower, Pilocarpus pennatifolius, Rutaceae

RESUMO - (Morfologia e anatomia da flor de Pilocarpus pennatifolius Lem. (Rutaceae)). Pilocarpus pennatifolius Lem. (Rutaceae) apresenta flores actinomorfas, diclamídeas, nectaríferas e monoclinas, reunidas em cacho pendente. Apresenta antese basípeta na inflorescência e preferencialmente noturna. A flor possui cinco estames com anteras tetrasporangiadas, cuja parede é constituída de epiderme, endotécio, duas camadas médias e tapete binucleado; o conectivo mostra epiderme estomatífera. $\mathrm{O}$ gineceu é unipistilado e composto por cinco carpelos unidos na região basal do ovário e no estilete e estigma. $\mathrm{O}$ estilete é curto e sólido e o estigma tem epiderme papilosa. O rudimento seminal (óvulo) é hemítropo, bitegumentado, crassinucelado e provido de hipóstase e possui obturador de origem funicular. O nectário envolve completamente a base do ovário. Cada sépala recebe três traços vasculares e as pétalas e estames apenas um; cada carpelo recebe um feixe vascular dorsal e dois ventrais, que mantêm individualidade em todo seu curso.

Palavras-chave - anatomia, antese, flor, Pilocarpus pennatifolius, Rutaceae

\section{Introdução}

Pilocarpus pennatifolius Lem., conhecida vulgarmente como jaborandi e cutia-branca, ocorre no Paraguai, na Argentina e, no Brasil, nos Estados de São Paulo, Paraná, Santa Catarina e Rio Grande do Sul. Ela é usada popularmente como diurética e diaforética. Essa planta contém princípio ativo denominado pilocarpina, que causa contração da pupila do olho, aumenta a produção de saliva, a produção normal de suor e o movimento peristáltico dos intestinos (Cowan \& Smith 1973).

A importância medicinal, econômica e ecológica de espécies nativas brasileiras, bem como o risco de sua extinção pela ação predatória do homem, têm motivado o estudo destas plantas, visando sua preservação e aproveitamento racional pelo homem.

\footnotetext{
1. Universidade Estadual de Maringá, Avenida Colombo, 5790, 87020-900 Maringá, Paraná, Brasil.

2._Autor para correspondência: lasouza@uem.br
}

Todavia, qualquer estudo de conservação exige informações básicas sobre seus órgãos de reprodução, principalmente sua morfologia e estrutura.

A família Rutaceae apresenta poucos representantes nos remanescentes florestais do norte do Paraná, uma região com menos de $1 \%$ de cobertura vegetal. Além de Pilocarpus pennatifolius ocorrem nessa região espécies dos gêneros Fagara, Esenbeckia, Metrodorea e Balfourodendron. A literatura botânica registra poucos trabalhos referentes à morfo-anatomia da flor de espécies dessa família, podendo ser citados Boesewinkel (1977, 1978), Boesewinkel \& Bouman (1978) e Beltrati (1991), que analisaram a estrutura de óvulos de espécies de Rutaceae; Marquete (1981), que estudou a anatomia e vascularização da flor de Pilocarpus organensis Occhioni \& Rizzini; Piedade \& Ranga (1993), que estudaram a biologia floral de Galipea jasminiflora Engler; Moreira \& Arnaez (1994), que estudaram a morfologia da flor de Zanthoxylum mayanum Standl., uma espécie de Costa Rica; Barbosa (1999) que estudou a polinização de Hortia brasiliana 
Vand., espécie que ocorre no cerrado do sudeste brasileiro.

Assim, a morfologia e a estrutura da flor de Pilocarpus pennatifolius foram objetos do presente trabalho. O estudo morfológico foi complementado com análise do período e do processo de floração da espécie.

\section{Material e métodos}

As observações e coletas de material botânico, ramos com botões e flores, foram feitas em oito exemplares da espécie ocorrentes no Horto Florestal de Maringá, área florestal de 37 hectares situada entre os meridianos $51^{\circ} 30^{\prime} \mathrm{e}$ $54^{\circ} \mathrm{W}$ e os paralelos $22^{\circ} 30^{\prime}$ e $24^{\circ} 30^{\prime} \mathrm{S}$, numa altitude média de $556 \mathrm{~m}$, durante os anos de 1999 e 2000. Parte do material coletado foi usada para montagem de exsicatas, para a devida identificação, registro e arquivo da espécie no Herbário da Universidade Estadual de Maringá (HUM), e o restante para análise morfo-anatômica.

As análises morfológica e estrutural dos botões e flores foram feitas em material fresco e fixado em FAA 50 (Johansen 1940). O material fresco foi seccionado transversal e longitudinalmente à mão livre, corado com safrablau e montado entre lâmina e lamínula (lâminas temporárias e semipermanentes) (Gerlach 1969). As lâminas permanentes foram preparadas com material fixado e emblocado em parafina e seccionado transversal e longitudinalmente ao micrótomo rotativo, segundo técnica descrita por Johansen (1940). A coloração das secções foi feita em hematoxilina e safranina, segundo método simplificado de Dnyansagar (1958), que consiste em corar as secções parafinadas, sem passar pelo processo de desparafinação e coloração segundo Johansen (1940).

Foram realizados testes para celulose, lignina, tanino e substância de caráter lipídico (Johansen 1940, Rawlins \& Takahashi 1952, Berlyn \& Mikshe 1976). Os desenhos e diagramas foram elaborados com o auxílio de câmara clara, projetando-se, nas mesmas condições ópticas, a escala correspondente.

O estudo morfológico foi complementado com observações sobre floração, definido como o desenvolvimento das flores compreendido desde o momento de antese (abertura da flor) até a fase de senescência do perianto e estames (Font Quer 1985). A floração foi acompanhada semanalmente nos oito exemplares da espécie distribuídos em pontos diferentes da mata. As observações sobre a antese foram feitas em dois espécimes da mata previamente marcados, no final do mês de maio do ano 2000 , cuja temperatura variou de 11 a $19^{\circ} \mathrm{C}$ e a umidade relativa de 68 a $94 \%$.

Material estudado - Pilocarpus pennatifolius Lem.: BRASIL: PARANÁ: Maringá, Horto Florestal de Maringá, 16-VII-1999, A. Souza 1 (HUM 4764); Maringá, Horto Florestal de Maringá, 16-VII-1999, A. Souza 2 (HUM 4765).

\section{Resultados}

Morfologia da flor e floração - As flores são diminutas, pentâmeras, actinomorfas, diclamídeas e monoclinas (figuras 3,4), e se reúnem em inflorescências terminais pendentes tipo cacho. Essas inflorescências apresentam em média 178 flores e medem aproximadamente $40 \mathrm{~cm}$ de comprimento. As flores possuem odor forte e desagradável, com sépalas muito reduzidas (figura 3) e de cor verde, pétalas vermelhas, estames com filetes vermelhos e anteras amarelas e gineceu unipistilado (figura 4). O gineceu apresenta ovário súpero com cinco carpelos unidos em sua base e livres em seu ápice (figuras 5, 10-13). Já na região do estilete e estigma os carpelos são também fusionados (figuras 5, 12-14). O nectário ocorre na base do ovário, envolvendo-o completamente (figuras 5, 10).

A floração ocorre de fevereiro a julho, mas é possível encontrar espécimes com botões ou flores em outros meses do ano. A antese na inflorescência é basípeta. Quando se aproxima o período de antese os botões florais verdes tornam-se vermelhos. Na base da corola dos botões formam-se pequenas fendas entre as pétalas que evoluem até o ápice expondo os estames e o pistilo (figuras 1-3). Não é raro ocorrer o aumento de apenas uma fenda liberando um estame (figura 2). Logo após a exposição dos órgãos reprodutores, as pétalas se afastam gradativamente e assumem a posição horizontal na flor (figura 4). A antese é, preferencialmente, noturna, verificando-se também o processo durante o dia, principalmente em dias nublados e chuvosos.

Anatomia da flor - As pétalas apresentam epiderme unisseriada, cuticularizada (figura 15) e estomatífera. Os estômatos apresentam-se elevados e presentes somente na face adaxial. A epiderme na face abaxial é papilosa. O mesofilo é de natureza parenquimática e colenquimática, formado por vários estratos de células de tamanho e formato variáveis (figura 15). Nele ocorrem ainda células com drusas (figura 15) e cavidades secretoras (figuras 5, 9, 10). As sépalas apresentam epiderme e mesofilo semelhantes às pétalas.

As anteras maduras são tetrasporangiadas (figura 16). No conectivo ocorrem, além do feixe vascular, tecido parenquimático e tecido, cujas células apresentam espessamentos parietais secundários lignificados helicoidais ou então reduzidos a uma ou duas faixas de parede secundária, que envolvem completamente a célula (figuras 16, 19,21). A epiderme, na região do conectivo, apresenta complexos estomáticos e células com ou sem espessamentos parietais secundários (figuras 20,21). Na antera jovem, 
fase em que há células-mãe de micrósporos (figura 17), os estratos parietais estão constituídos pela epiderme, camada precursora do endotécio de células de paredes delgadas, duas camadas médias e tapete secretor binucleado. Na parede da antera já madura ocorrem: epiderme glabra, revestida por cutícula estriada, endotécio com células colunares que apresentam espessamento parietal secundário lignificado, disposto também helicoidalmente ou em duas ou três faixas (figuras 18,19), e camadas médias pouco comprimidas; o tapete está ausente nesta fase, devido sua desintegração em fase anterior (figuras 16, 18).

O estigma (figura 5), distingue-se do estilete por pequenas reentrâncias apicais e pela epiderme de células prismáticas papilosas (figura 22). Logo abaixo da epiderme ocorrem células parenquimáticas de dimensões reduzidas e notáveis cavidades secretoras. O estilete é formado por epiderme simples, com pêlos glandulares, parênquima com amplas cavidades secretoras (figuras 14,24 ) e cordões de tecido
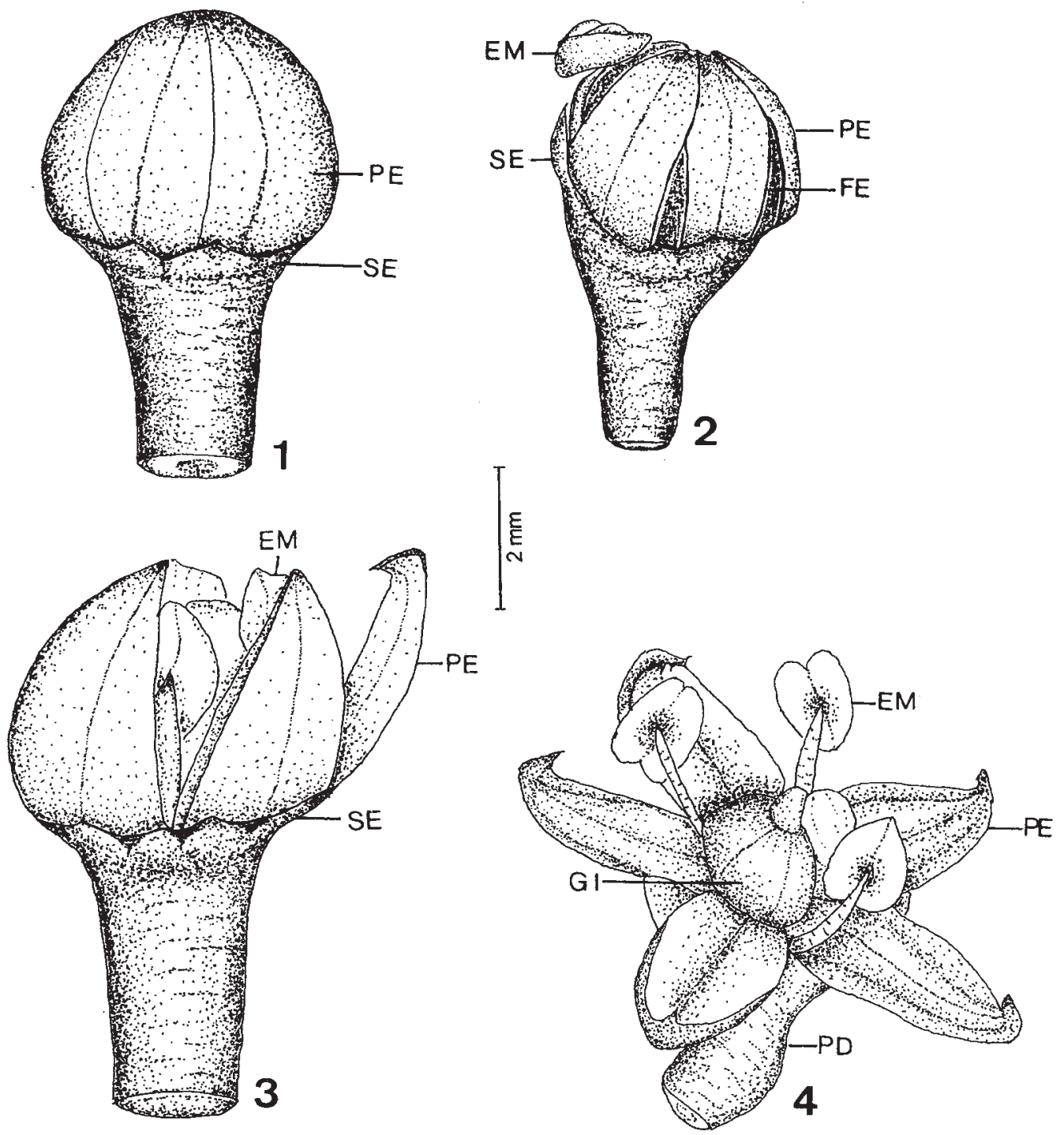

Figuras 1-4. Antese. 1. Botão floral. 2. Botão floral apresentando fendas basais na corola e estame exposto. 3. Botão parcialmente aberto expondo estames. 4. Flor aberta, sem um estame. EM - estame; FE - fenda; GI - gineceu; PD - pedúnculo; PE - pétala; SE - sépala.

Figures 1-4. Anthesis. 1. Floral bud. 2. Floral bud presenting basal rifts in the corolla and anther exposed. 3. Floral bud with anthers exposed. 4. Flower with anthers and stigma exposed. EM - stamen; FE - rift; GI - gynoecium; PD - pedicel; PE - petal; SE - sepal. 

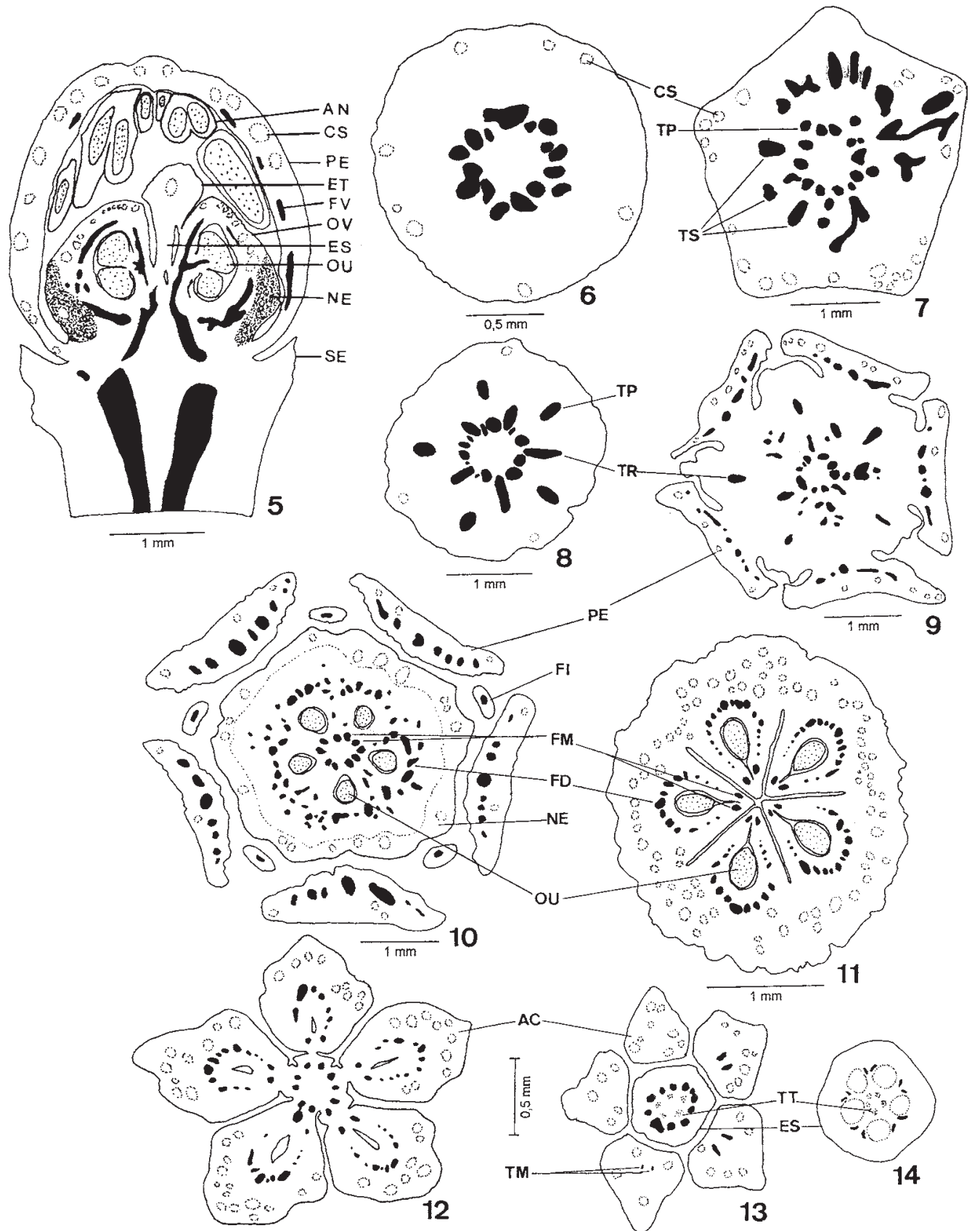

Figuras 5-14. Diagramas de secções de botão floral e flor. 5. Secção longitudinal de botão. 6-14. Secções transversais de flor. 6. Pedúnculo floral. 7-9. Receptáculo floral em níveis sucessivos. 10. Região do nectário e base do ovário. 11. Região média do ovário, sem pétalas e estames. 12-13. Ápice do ovário, sem pétalas e estames. 14. Estilete, nas proximidades do estigma. AC - ápice do carpelo; AN - antera; CS - cavidade secretora; ES - estilete; ET - estigma; FD - feixe dorsal; FI - filete; FM feixes marginais ou ventrais; FV - feixe vascular; NE - nectário; OU - rudimento seminal (óvulo); OV - ovário; PE - pétala; SE - sépala; TM - terminação de feixes marginais; TP - traço de pétala; TR - traço de estame; TS - traço de sépala; TT - tecido transmissor.

Figures 5-14. Diagrams of floral bud and flower. 5. Floral bud in longitudinal section. 6-14. Flower in cross-sections. 6. Pedicel. 7-9. Receptacle in successive levels. 10. Nectary region and ovary basal region. 11. Ovary medium region, lacking petals and stamens. 12-13. Ovary apical region lacking petals and stamens. 14. Style close to the stigma. AC - Carpell apical region; AN anther; CS - secretory cavity; ES - style; ET - stigma; FD - dorsal vascular bundle; FI - filament; FM - marginal or ventral vascular bundle; FV - vascular bundle; NE - nectary; OU - ovule; OV - ovary; PE - petal; SE - sepal; TM - termination of the marginal vascular bundles; TP - petal trace; TR - stamen trace; TS - sepal trace; TT - transmitting tissue. 

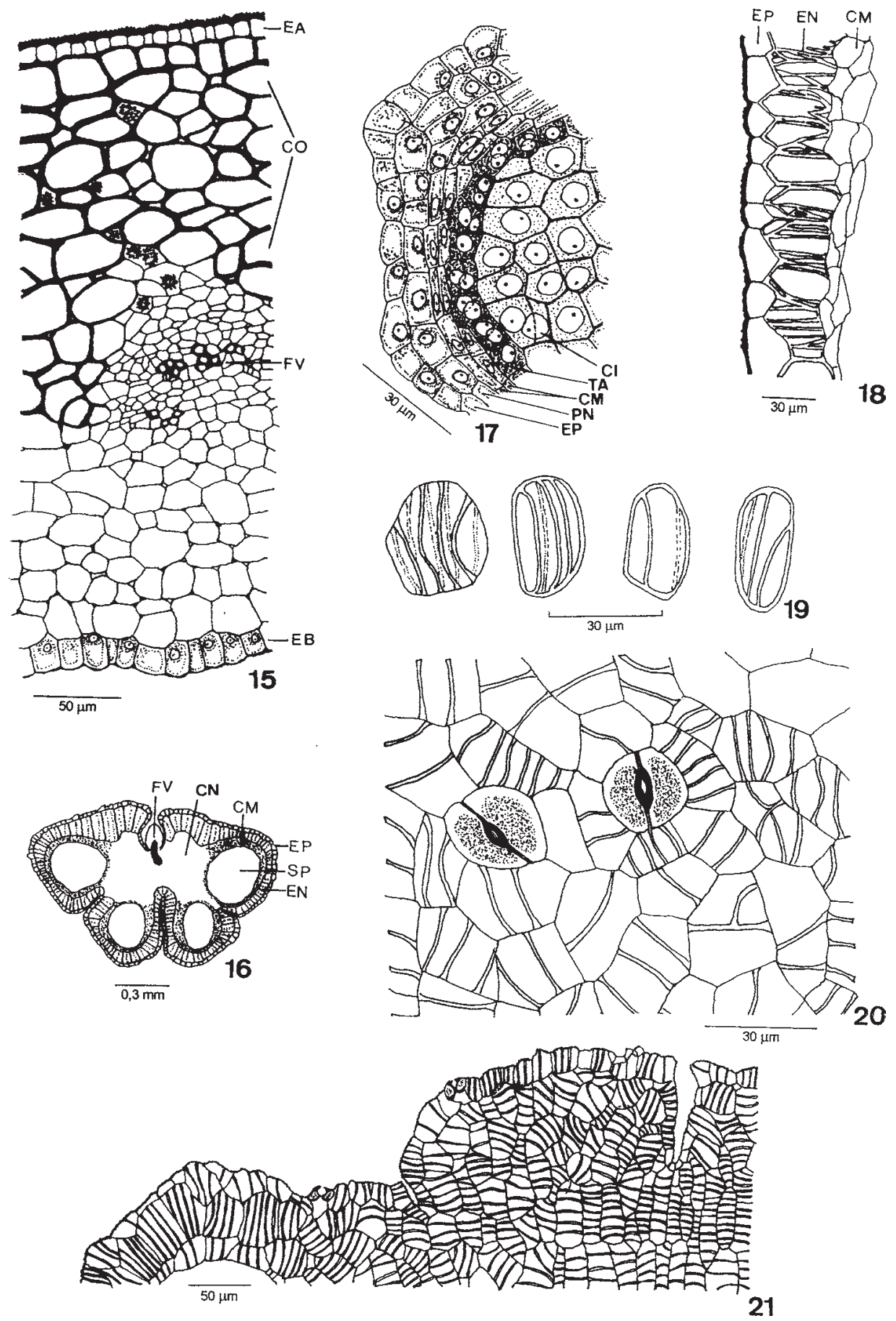

Figuras 15-21. Pétala e antera. 15. Pormenor anatômico da pétala, em secção transversal. 16. Diagrama da secção transversal da antera. 17-18. Pormenores da parede da antera jovem e madura. 19. Células isoladas do endotécio e do conectivo. 20. Epiderme da região do conectivo, em vista frontal. 21. Parte do conectivo, em secção transversal. CI - células-mãe de micrósporo; $\mathrm{CM}$ - camadas médias; $\mathrm{CN}$ - conectivo; $\mathrm{CO}$ - colênquima; EA - epiderme da face adaxial; EB - epiderme da face abaxial; EN - endotécio; EP - epiderme; FV - feixe vascular; PA - parênquima; PN - precursor do endotécio; SP - saco polínico; TA tapete.

Figures 15-21. Petal and anther. 15. Detail of the petal, in cross-section. 16. Diagram of the anther in cross-section. 17-18. Detail of the young and mature anther wall. 19. Cells of the endothecium and connective. 20. Epidermis of the connective, in frontal view. 21. Connective in cross-section. CI - microspore mother cells; CM - middle layers; $\mathrm{CN}$ - connective; $\mathrm{CO}$ - collenchyma; EA - adaxial surface of the epidermis; EB - abaxial surface of the epidermis; EN - endothecium; EP - epidermis; FV - vascular bundle; PA - parenchyma; PN - immature endothecium; SP - pollen sac; TA - tapetum. 
transmissor, um para cada carpelo (figuras 13, 14, 24); estes cordões reúnem-se na região central do estilete, já nas proximidades do estigma. O ovário mostra epiderme com estrato simples de células, revestido por cutícula estriada, e estômatos (figura 25). Na epiderme observam-se poucos pêlos glandulares pluricelulares, com o ápice secretor multicelular e pedúnculo muito reduzido (figura 23). O tecido fundamental ovariano é parenquimático e apresenta conspícuas cavidades secretoras (figuras 5, 25). A epiderme interna do ovário, ainda na fase de pré-antese, assume atividade meristemática, caracterizada pela ocorrência de divisões celulares anticlinais e principalmente periclinais (figura 25).

Os rudimentos seminais (óvulos), dois por lóculo (figura 5), são hemítropos, bitegumentados, crassinucelados e providos de hipóstase (figura 26), com células de conteúdo fenólico. O canal micropilar é formado pela exóstoma e endóstoma, sendo as aberturas não coincidentes (figura 26). Os tegumentos cuticularizados possuem três a quatro camadas de células em sua base e apresentam mais estratos nas extremidades, ampliando-se desta forma na região da micrópila. Há obturador de origem funicular (figura 26).

O nectário (figuras 5, 10) possui epiderme unisseriada, papilosa, com cutícula estriada e estômatos, e tecido secretor de células diminutas e de citoplasma relativamente denso, no qual se destacam células cristalíferas com drusas e também muitas cavidades secretoras (figura 27). A vascularização do nectário (figura 5) é feita predominantemente pelo floema. Vascularização da flor - No pedúnculo floral, o cilindro central é caracterizado pela presença de vários feixes vasculares colaterais que circundam uma medula parenquimática (figura 6). Nas proximidades do receptáculo da flor começam a ser definidos os traços das sépalas (figura 7). As sépalas apresentam três traços e as pétalas apenas um (figuras 7,8 ). O único traço já na base da pétala se divide num feixe central maior e vários outros de menor calibre (figura 9). Os estames apresentam também somente um traço (figuras 8,9), que se mantém como feixe vascular indiviso (figura 10) até a antera, na região do conectivo (figura 16). Os carpelos têm vascularização mais complexa. Os traços carpelares, inicialmente dois para cada carpelo (figura 8 ), se separam em vários (figuras 9, 10). Assim, em cada carpelo, permanecem na região central do receptáculo dois feixes que se definem mais acima como feixes marginais ou ventrais e vários traços que se afastam constituindo os feixes dorsais e laterais (figuras 10-12). A vascularização de cada carpelo mantém-se independente uma da outra desde o receptáculo floral, e conserva-se até a base do estilete (figura 12). Nesta região os feixes marginais do ovário se ramificam constituindo os dois feixes do estilete de cada carpelo que terminam na base do estigma (figuras 12-14). Os feixes marginais, dorsais e laterais do ovário apresentam suas terminações nos ápices dos carpelos completamente livres (figuras 12, 13).

\section{Discussão}

As inflorescências racemosas, rígidas e pendentes, a antese principalmente noturna, as flores vermelhas e o nectário localizado na base do ovário de Pilocarpus pennatifolius são algumas das características registradas por Faegri \& van der Pijl (1971) na descrição da síndrome de falenofilia. Os tipos de polinização na família Rutaceae são bem variados, ocorrendo principalmente entomofilia (Engler 1931), com insetos do grupo das moscas e vespas (Kuhlmann \& Kuhn 1947 apud Barbosa 1999). Bawa et al. (1985) baseados na morfologia floral inferiram que duas espécies dióicas de Zanthoxylum, sejam polinizadas por pequenos insetos. No presente estudo não foi analisado o tipo de polinização de Pilocarpus pennatifolius, mas observações diurnas e noturnas realizadas durante o período de floração dessa espécie mostraram a presença de mariposas visitando suas flores à noite. Estas observações associadas às características morfológicas da flor e inflorescência dessa espécie sugerem que ela possa ser polinizada por esses insetos.

As pétalas de Pilocarpus pennatifolius apresentam feixes vasculares pouco desenvolvidos e são desprovidas também de esclerênquima, o que é comum em Angiospermas. Fahn (1974) e Mauseth (1988) consideram as pétalas estruturas delicadas e efêmeras, não necessitando, portanto, de alta capacidade na função de condução e de sustentação.

O gineceu de Pilocarpus pennatifolius mostra os carpelos unidos na base e separados na região média e superior do ovário. No estilete e no estigma os carpelos são fundidos. A análise da vascularização floral do gineceu desta espécie revelou que a fusão dos carpelos na base do ovário não acarreta qualquer efeito sobre seus feixes vasculares marginais ou ventrais e dorsal. Esses feixes mantêm-se individualizados, sem qualquer fusão dentro do mesmo carpelo ou com feixes de carpelos contíguos. Essa interpretação favorece a apocarpia em Pilocarpus pennatifolius, levando-se em conta o efeito provocado pelo processo de coesão sobre o sistema vascular carpelar considerado por Eames \& 

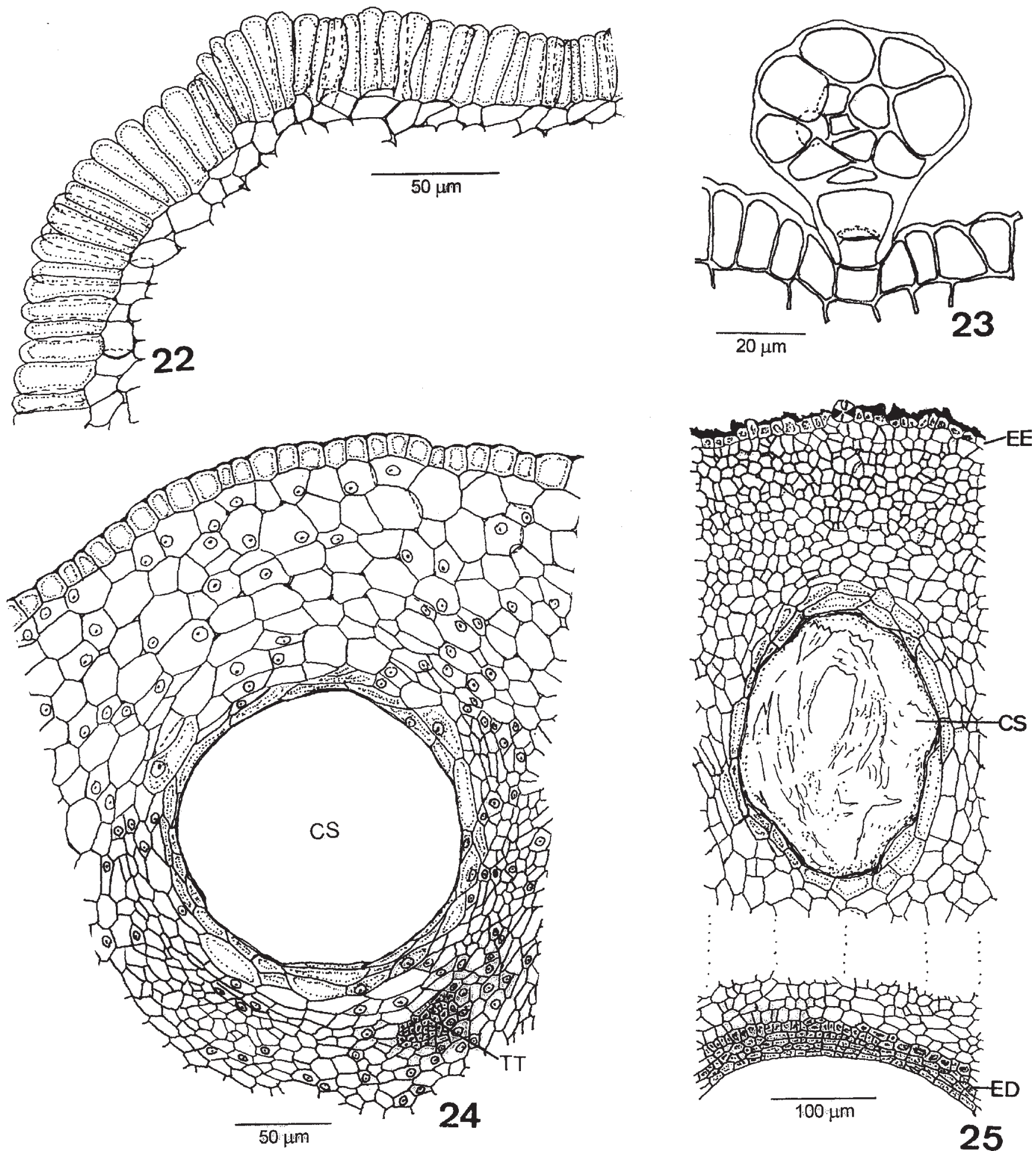

Figuras 22-25. Gineceu. 22. Pormenor anatômico da epiderme estigmática. 23. Pêlo glandular do ovário e estilete. 24. Pormenor do estilete, em secção transversal. 25. Pormenor da parede do ovário, em secção transversal. CS - cavidade secretora; ED epiderme interna multisseriada; EE - epiderme externa; TT - tecido transmissor.

Figures 22-25. Gynoecium. 22. Detail of the stigma epidermis. 23. glandular trichome of the ovary and style. 24. Detail of the style in cross-section. 25. Detail of ovary wall in cross-section. CS - secretory cavity; ED - inner multiple epidermis; EE - outer epidermis; TT - transmitting tissue. 


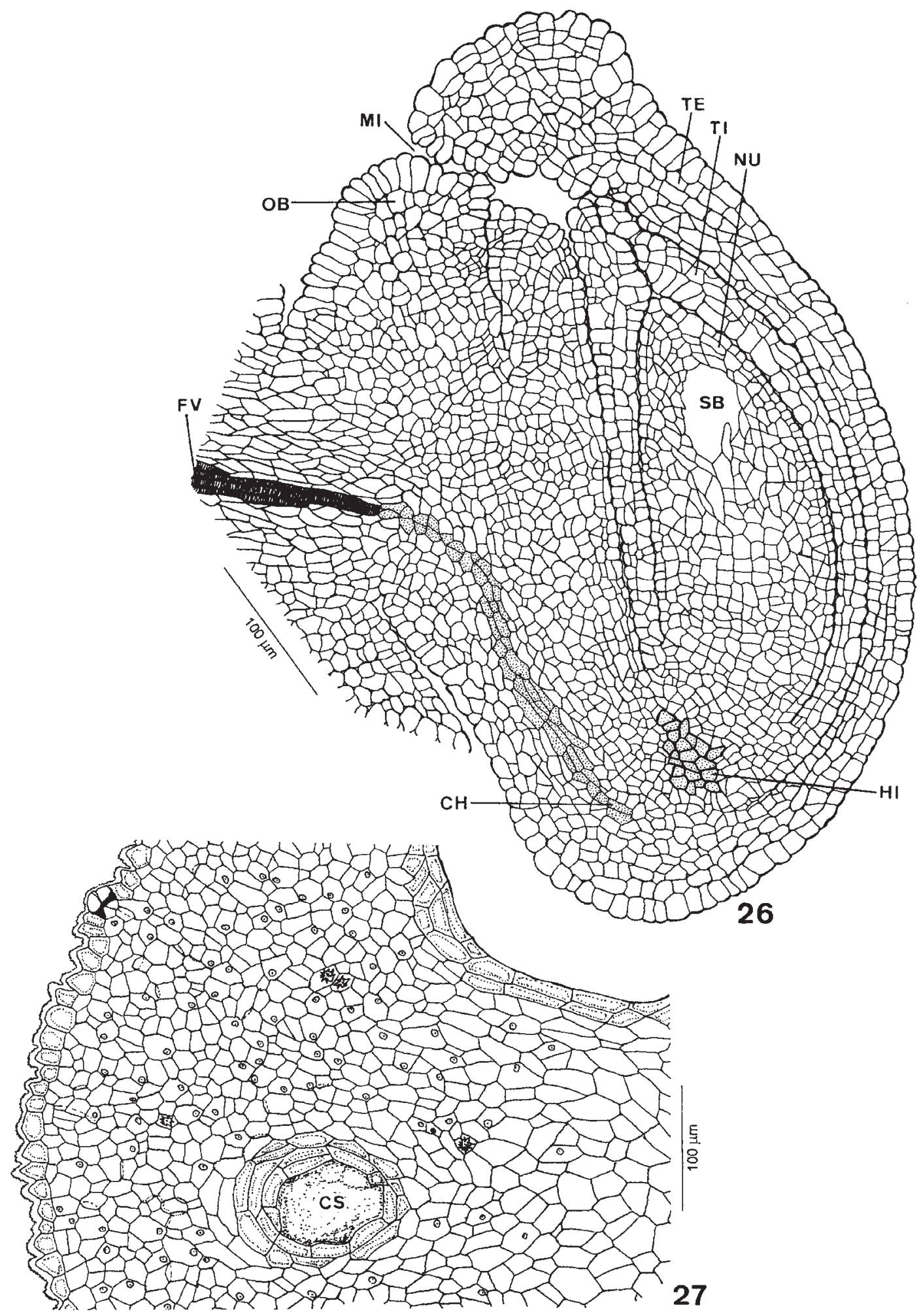

Figura 26. Rudimento seminal (óvulo) em secção longitudinal. Figura 27. Nectário em secção longitudinal. CH - chalaza; CS - cavidade secretora; FV - feixe vascular; HI - hipóstase; MI - micrópila; NU - nucelo; OB - obturador; SB - saco embrionário; TE - tegumento externo; TI - tegumento interno.

Figure 26. Ovule in longitudinal section. Figure 27. Nectary in longitudinal section. CH - chalaza; CS - secretory cavity; FV vascular bundle; HI - hypostase; MI - micropyle; NU - nucellus; OB - obturator; SB - embryonic sac; TE - outer integument; TI - inner integument. 
MacDaniels (1953). Ademais, Marquete (1981), analisando o gineceu de Pilocarpus organensis, considerou-o com os carpelos livres, sem levar em conta a fusão verificada na base ovariana, estilete e estigma desta espécie. Ressalta-se, também, que observações sobre o desenvolvimento do ovário em fruto de Pilocarpus pennatifolius, após a senescência do estigma e estilete (A. Souza, dados não publicados), acentua a separação dos carpelos, caracterizando o fruto como apocárpico ou esquizocárpico de Spjut (1994). Esse fruto, considerado como derivado de um pistilo composto, que se divide na maturidade em unidades carpelares cada qual com sua semente (Spjut 1994), origina-se de ovários ou carpelos que são unidos na base e no estilete e estigma, como ocorre na espécie em estudo.

$\mathrm{Na}$ fase ainda de pré-antese a epiderme interna do ovário de Pilocarpus pennatifolius divide-se periclinalmente. Essa atividade meristemática da epiderme ovariana é freqüente nas famílias Rutaceae e Fabaceae e origina epiderme interna multisseriada, o conhecido "seed cushion", nos frutos de espécies dessas famílias (Roth 1977, Souza 1984). Observações adicionais sobre o desenvolvimento do pericarpo de Pilocarpus pennatifolius (A. Souza, dados não publicados) mostraram que a atividade meristemática da epiderme interna de seu ovário pode originar a epiderme multisseriada e também o tecido esclerenquimático (endocarpo) que ocorrem em seu fruto maduro. Aliás, a ação de um meristema ovariano epidérmico pode originar em frutos secos tecido esclerenquimático que participa ativamente do processo de deiscência do pericarpo, como verificado em espécies de Rutaceae e Fabaceae (Roth 1977, Souza 1984, 1993). No caso da espécie em estudo, que possui fruto seco e apresenta autocoria, esse meristema ventral instalado precocemente na parede do seu ovário deve contribuir no desenvolvimento do aparelho de deiscência de seu fruto.

Apesar dos rudimentos seminais das espécies da família Rutaceae e, especialmente, de Pilocarpus, terem sido descritos por Corner (1976) como anátropos, o rudimento seminal de Pilocarpus pennatifolius é hemítropo. Ele é semelhante ao registrado para outra rutácea Esenbeckia febrifuga por Beltrati (1991), mas difere, entretanto, na estrutura do obturador que é papiloso em Pilocarpus pennatifolius e piloso em Esenbeckia febrifuga. Obturador de origem funicular, semelhante ao de Pilocarpus pennatifolius, também foi descrito nas espécies estudadas por Boesewinkel $(1977,1978)$ e Boesewinkel \& Bouman (1978).
As células com conteúdo fenólico que estão presentes na região chalazal do rudimento seminal de Pilocarpus pennatifolius foram consideradas como hipóstase, termo proposto por Johansen (1928 apud Tilton 1980) e que designa todos os tipos de modificações da chalaza ou da região chalazal do rudimento. Tilton (1980), por sua vez, sugere que hipóstase deva ser definida como grupo de células modificadas com paredes geralmente lignificadas, presente na região chalazal do óvulo, mas que pode envolver uma parte do nucelo e estender-se parcialmente na região micropilar. Por outro lado, Teichman \& Wyk (1991) fazem distinção de uma hipóstase "stricto sensu" e outra "lato sensu". A primeira compreende um grupo de células nucelares com paredes levemente espessadas na extremidade chalazal do rudimento seminal, que não sofre qualquer extensão secundária nem participa da formação do tegumento seminal. A hipóstase "lato sensu" corresponde às células nucelares localizadas na região chalazal, que formam inicialmente uma placa celular discóide, com conteúdo taninífero, e sofrem extensiva proliferação secundária, participando do desenvolvimento do tegumento da semente. A hipóstase de Pilocarpus pennatifolius enquadra-se mais apropriadamente na definição proposta por Johansen (1928 apud Tilton 1980) e Tilton (1980).

O gênero Pilocarpus apresenta disco nectarífero anular na base do ovário (Cowan \& Smith 1973). Em Pilocarpus pennatifolius este disco não é tão evidente, apresentando-se como tecido nectarífero fundido à parede da base do ovário. Puri (1951) apresenta discussão sobre a origem desse disco na família Rutaceae. Segundo ele, o disco pode ser de natureza receptacular em algumas espécies, estaminodal em outras, e carpelar em ainda outras plantas. No caso de Pilocarpus pennatifolius, sua localização, vascularização e continuidade histológica com a parede do ovário, caracterizam-no como de origem carpelar.

A flor de Pilocarpus pennatifolius apresenta plano vascular floral típico ou básico proposto por Puri (1951). A sépala recebe diretamente do estelo três traços vasculares e a pétala e estame apenas um, sem que haja coesão ou adnação de qualquer dos traços vasculares. $O$ tecido estelar remanescente organiza-se num sifonostelo dissecado antes de originar os traços carpelares. Cada carpelo recebe feixe dorsal e ventrais ou marginais que mantêm sua individualidade em seu curso pela folha carpelar. Não há, portanto, nessa espécie, modificação desse plano por redução no número de feixes vasculares na flor, seja por perda de feixes num órgão ou por fusão de feixes. 


\section{Referências bibliográficas}

BARBOSA, A.A.A. 1999. Hortia brasiliana Vand. (Rutaceae): polinização por aves Passeiriformes no cerrado do sudeste brasileiro. Revista Brasileira de Botânica 22:99-105.

BAWA, K.S., PERRY, D.R. \& BEACH, J.H. 1985. Reproductive biology of tropical lowland rain forest trees. II Polination systems. American Journal of Botany 72:346-356

BELTRATI, C.M. 1991. Estudo morfo-anatômico das sementes e plântulas de Esenbeckia febrifuga (St. Hill.) A. Juss. ex Mart. (Rutaceae). Naturalia 16:161-169.

BERLYN, G.P. \& MIKSCHE, J.P. 1976. Botanical microtechnique and cytochemistry. The Iowa State University Press, Ames (Iowa).

BOESEWINKEL, F.D. 1977. Development of ovule and testa in Rutaceae I: Ruta, Zanthoxylum, and Skimmia. Acta Botanica Neerlandica 26:193-211.

BOESEWINKEL, F.D. 1978. Development of ovule and testa in Rutaceae III: Some representatives of the Aurantioideae. Acta Botanica Neerlandica 27:341-354.

BOESEWINKEL, F.D. \& BOUMAN, F. 1978. Development of ovule and testa in Rutaceae II: The unitegmic and pachychalazal seed of Glycosmis cf. arborea (Roxb.) D.C. Acta Botanica Neerlandica 27:69-78.

CORNER, E.J.H. 1976. The seeds of dicotyledons. Cambridge University Press, Cambridge.

COWAN, R.S. \& SMITH, L.B. 1973. Rutáceas. In Flora ilustrada catarinense (P.R. Reitz, ed.). Itajaí, Santa Catarina, p. I, p.24-30

DNYANSAGAR, V.R. 1958. Embryological studies in the Leguminosae VIII. Acacia auriculaeformis A Cunn., Adenanthera pavonina Linn., Calliandra grandiflora Benth. Lloydia 21:1-25.

EAMES, A.J. \& MACDANIELS, L.A. 1953. An introduction to plant anatomy. Tata McGraw-Hill Publishing, New Delhi.

ENGLER, A. 1931. Rutaceae, Simarubaceae, Burseraceae. In Die natürlichen Pflanzenfamilien, (A. Engler \& K. Prantl, eds.). Gebruder Borntraeger, Berlin, 219a, p.187-456.

FAEGRI, K. \& VAN DER PIJL, L. 1971. The principles of pollination ecology. Pergamon Press, Oxford.
FAHN, A. 1974. Plant anatomy. Pergamon Press, Oxford.

FONT QUER, P. 1985. Dicionario de botánica. Editorial Labor, Barcelona.

GERLACH, G. 1969. Botanische microtechnik, eine Einfiihrung. Georg Thiene, Stuttgart.

JOHANSEN, D.A. 1940. Plant microtechnique. McGraw-Hill Book Company, New York.

MARQUETE, O. 1981. Anatomia e vascularização foliar e floral de Pilocarpus organensis Occhioni \& Rizzini (Rutaceae). Arquivos do Jardim Botânico do Rio de Janeiro 25:117-159.

MAUSETH, J.D. 1988. Plant anatomy. The Benjamin/ Cummings Publishing Company, California.

MOREIRA, G.I. \& ARNAEZ, S.E. 1994. Morphology of reproductive structures and germination of nine native forestry species in Costa Rica. Revista de Biologia Tropical 42:73-82.

PIEDADE, L.H. \& RANGA, N.T. 1993. The pollination ecology of Galipea jasminiflora Engler (Rutaceae). Revista Brasileira de Botânica 16:151-157.

PURI, V. 1951. The role of floral anatomy in the solution of morphological problems. The Botanical Review 17:471-553.

RAWLINS, T.E. \& TAKAHASHI, W.N. 1952. Technics of plant histochemistry and virology. The National Press, Millbrae.

ROTH, I. 1977. Fruits of angiosperms. In Handbuch der Pflanzenanatomie, (K. Linsbauer, ed.). Gebruder Borntraeger, Berlin, v.10, p.47-49.

SOUZA, L.A. 1984. Anatomia do desenvolvimento do pericarpo de Lonchocarpus muehlbergianus Hassler (Leguminosae-Faboideae). Revista Unimar 6:5-19.

SOUZA, L.A. 1993. Morfo-anatomia do desenvolvimento do fruto de Acacia paniculata Willd. (Leguminosae). Arquivos de Biologia e Tecnologia 36:851-871.

SPJUT, R.W. 1994. A systematic treatment of fruit types. Memoirs of New York Botanical Garden 70:1-182.

TEICHMAN, I.VAN \& WYK, A.E.VAN 1991. Trends in the evolution of dicotyledons seeds based on character association, with special reference to pachychalazy and recalcitrante. Botanical Journal of Linnean Society of London 105:211-237.

TILTON, V.R. 1980. Hypostase development in Omithogalum caudatum (Liliaceae) and notes on the other types of modifications in chalaza de angiosperm ovules. Canadian Journal of Botany 58:2059-2066. 